CNS Spectrums (2017), 22, 220-227. (c) Cambridge University Press 2017. This is an Open Access article, distributed under the terms of the Creative Commons Attribution licence (http://creativecommons.org/licenses/by/4.0/), which permits unrestricted re-use, distribution, and reproduction in any medium, provided the original work is properly cited.

\title{
Remission and recovery associated with lurasidone in the treatment of major depressive disorder with subthreshold hypomanic symptoms (mixed features): post-hoc analysis of a randomized, placebo-controlled study with longer-term extension
}

\author{
Joseph F. Goldberg, ${ }^{1}$ Daisy Ng-Mak, ${ }^{2 *}$ Cynthia Siu ${ }^{3}$ Chien-Chia Chuang, ${ }^{2}$ \\ Krithika Rajagopalan, ${ }^{2}$ and Antony Loebel ${ }^{4}$
}

\footnotetext{
${ }^{1}$ Icahn School of Medicine at Mount Sinai, New York, New York, USA

${ }^{2}$ Global Health Economics and Outcomes Research, Sunovion Pharmaceuticals Inc., Marlborough, Massachusetts, USA

${ }^{3}$ COS and Associates Ltd., Central, Hong Kong, People's Republic of China

${ }^{4}$ Research and Development, Sunovion Pharmaceuticals Inc., Fort Lee, New Jersey, USA
}

Objective. This post-hoc analysis assessed rates of symptomatic and functional remission, as well as recovery (combination of symptomatic and functional remission), in patients treated with lurasidone for major depressive disorder (MDD) associated with subthreshold hypomanic symptoms (mixed features).

Method. Patients with MDD plus two or three manic symptoms (defined as per the DSM-5 mixed-features specifier) were randomly assigned to flexible-dose lurasidone $20-60 \mathrm{mg} /$ day $(n=109)$ or placebo $(n=100)$ for 6 weeks, followed by a 3-month open-label, flexible-dose extension study for U.S. sites only $(n=48)$. Cross-sectional recovery was defined as the presence of both symptomatic remission (Montgomery-Åsberg Depression Rating Scale score $\leq 12$ ) and functional remission (all Sheehan Disability Scale [SDS] domain scores $\leq 3$ ) at week 6 , and at both months 1 and 3 of the extension study ("sustained recovery").

Results. A significantly higher proportion of lurasidone-treated patients (31.3\%) achieved recovery (assessed crosssectionally) compared to placebo $(12.2 \%, p=0.002)$ at week 6 . The number of manic symptoms at baseline moderated the effect size for attaining cross-sectional recovery for lurasidone treatment (vs. placebo) $(p=0.028)$. Sustained recovery rates were higher in patients initially treated with lurasidone $(20.8 \%)$ versus placebo $(12.5 \%)$.

Conclusions. In this post-hoc analysis of a placebo-controlled study with open-label extension that involved patients with MDD and mixed features, lurasidone was found to significantly improve the rate of recovery at 6 weeks (vs. placebo) that was sustained at month 3 of the extension study. The presence of two (as opposed to three) manic symptoms moderated recovery at the acute study endpoint.

Received 9 June 2016; Accepted 21 September 2016; First published online 7 March 2017

Key words: Major depressive disorder, mixed features, functional remission combined symptomatic and functional remission, lurasidone.

* Address correspondence to: Daisy Ng-Mak, Global Health Economics and Outcomes Research, Sunovion Pharmaceuticals Inc., 84 Waterford Drive, Marlborough, Massachusetts 01748, USA.

(Email: Daisy.Ng-Mak@Sunovion.com)

This study is registered at Clinicaltrials.gov (no. NCT01421134) and Clinicaltrials.gov (no. NCT01423253).

This research was supported by Sunovion Pharmaceuticals Inc., Marlborough, Massachusetts, USA.

\section{Introduction}

Manic symptoms below the threshold for hypomania (mixed features) are prevalent in people with major depressive disorder (MDD). ${ }^{1-7}$ In the National Comorbidity Survey Replication (NCS-R) study, a nationally representative, face-to-face, household survey of the U.S. population conducted between February of 2001 and 
April of 2003 , nearly $40 \%$ of study participants with a history of MDD had subthreshold hypomania (defined as the presence of three or more manic symptoms). ${ }^{2}$ Previous reports suggested that, compared to pure major depression, major depressive disorder with mixed features is associated with greater illness severity, ${ }^{8-11}$ increased frequency of recurrent depressive episodes, ${ }^{2,11}$ increased risk of suicide attempts, ${ }^{2,7,11-13}$ a high frequency of substance abuse, ${ }^{2,7,11}$ and greater functional impairment. ${ }^{2,6,11}$ MDD with mixed features has recently been endorsed as a clinically distinct and valid entity by its inclusion in the Diagnostic and Statistical Manual of Mental Disorders, 5h ed. (DSM-5). ${ }^{14}$

Lurasidone is an atypical antipsychotic agent with high affinity for $\mathrm{D}_{2}, 5-\mathrm{HT}_{2 \mathrm{~A}}$, and $5-\mathrm{HT}_{7}$ receptors $\left(K_{i}=1,0.5\right.$, and $0.495 \mathrm{nM}$, respectively). ${ }^{15}$ In animal models, the antidepressant effect of lurasidone has been shown to be mediated in part by antagonist activity at the $5-\mathrm{HT}_{7}$ receptor. ${ }^{16-17}$ Lurasidone has demonstrated efficacy in the treatment of major depressive episodes associated with bipolar I disorder (bipolar depression), both as a monotherapy and as an adjunctive therapy with lithium or valproate. ${ }^{18,19}$ A recent placebo-controlled trial demonstrated the efficacy and safety of lurasidone for MDD with subthreshold hypomanic symptoms. ${ }^{20}$

Symptomatic remission and reduction in functional impairment is considered necessary for meaningful recovery from psychiatric disorders. ${ }^{21-23}$ A recent study evaluated recovery in bipolar depression based on rates of combined symptomatic and functional remission sustained over time. ${ }^{23}$ A majority of patients with bipolar depression initially treated with lurasidone in the acute phase attained recovery status during the 6-month continuation study, and treatment with lurasidone (vs. placebo) earlier in the course of a bipolar depressive episode increased the likelihood of subsequent recovery. The objectives of our post-hoc analysis were to investigate the proportion of, and predictors for, combined symptomatic and functional remission at short-term (6 weeks) and extension (3 months) study endpoints among patients with major depressive disorder associated with subthreshold hypomanic symptoms (mixed features).

\section{Methods}

A post-hoc analysis was conducted using data from a previously reported double-blind, placebo-controlled, 6-week trial in patients with major depressive disorder associated with subthreshold hypomanic symptoms (mixed features) (Clinicaltrials.gov, no. NCT01421134), ${ }^{20}$ which was followed by a 3-month open-label extension study with lurasidone (Clinicaltrials.gov, no. NCT01423253). The present study was approved by the institutional review board at each investigational site and was conducted in accordance with the International Council on Harmonisation of
Technical Requirements for Registration of Pharmaceuticals for Human Use-Good Clinical Practice guidelines, and with the ethical principles of the Declaration of Helsinki.

\section{Patients}

This study enrolled outpatients 18-75 years of age diagnosed with major depressive disorder who were experiencing a major depressive episode (based on DSMIV-TR criteria), with a score $>26$ on the MontgomeryÅsberg Depression Rating Scale (MADRS) ${ }^{24}$ at both the screening and baseline visits. Diagnosis was confirmed by an experienced and qualified rater using the Structured Clinical Interview for DSM-IV Disorders-Clinical Trial version (SCID-CT) modified to record the presence of mixed (hypomanic) symptoms. ${ }^{25}$ In addition, patients were required to have two or three of the following manic symptoms, on most days, for at least 2 weeks prior to screening: elevated or expansive mood, inflated self-esteem or grandiosity, more talkative than usual or pressure to keep talking, flight of ideas or racing thoughts, increased energy, increased or excessive involvement in activities with a high potential for negative consequences, and decreased need for sleep. Independent external reviewers verified the diagnoses of all study participants, based on audiotaped recordings of diagnostic interviews conducted by site-based investigators.

\section{Study design}

This randomized, double-blind, placebo-controlled, flexible-dose study enrolled a total of 211 patients at 18 sites in the United States ( $n=62$ patients) and at 26 sites in Europe ( $n=149$ patients) between September of 2011 and October of 2014. After a washout period of at least 3 days, patients were randomly assigned, in a 1:1 ratio, to 6 weeks of treatment with lurasidone or placebo. Study medication was taken once daily in the evening with a meal or within 30 minutes after eating. Patients assigned to receive lurasidone were treated with $20 \mathrm{mg} /$ day for days 1-7. Patients were dosed flexibly, in the range of 20-60 mg/day, starting on day 8. The U.S. patients who completed the 6-week, double-blind, placebo-controlled, core study were eligible to participate in an open-label, 3 -month extension study, where lurasidone was flexibly adjusted (i.e., 20, 40, or $60 \mathrm{mg}$ /day), based on clinical judgment, in order to optimize efficacy and tolerability.

\section{Outcomes}

The MADRS is a 10-item, clinician-rated assessment of severity of depression, with higher scores associated with greater severity of depression. ${ }^{24}$ The Clinical Global Impressions Severity subscale (CGI-S) score rates overall illness severity on a 7-point scale, with higher scores associated with greater illness severity. ${ }^{26}$ The Sheehan 
Disability Scale $(\mathrm{SDS})^{27}$ is a well-established self-rated scale designed to assess level of functional impairment across three major functional domains, in which patients rate the extent to which (1) work, (2) social life or leisure activities, and (3) home life or family responsibilities are impaired by mood symptoms on 10-point visual analog scales $(0=$ "not at all," 1-3 = "mildly," 4-6 = "moderately," 7-9 = "markedly," and $10=$ "extremely"), with higher scores reflecting greater functional impairment. MADRS and CGI-S scores were assessed at core baseline, week 6 (end of double-blind core phase), and at months 1,2 , and 3 of the extension study. SDS scores were assessed at core baseline, week 6 , and at months 1 and 3 of the extension study. We defined symptomatic remission as a MADRS total score $<12$ and functional remission as all SDS domain scores $<3$ (representing mild or absent functional impairment). ${ }^{23,27}$ Recovery was defined as the presence of both symptomatic remission (MADRS score $\leq 12$ ) and functional remission (all SDS domain scores $\leq 3$ ) at week 6 ("cross-sectional recovery"), and at both months 1 and 3 of the extension study ("sustained recovery"). Sensitivity analyses were performed using a MADRS score of $<8$ to assess rates of symptomatic remission and all SDS domain scores $<2$ to assess functional remission at week 6 .

\section{Statistical methods}

In the present post-hoc analysis, a logistic regression model was applied to evaluate the effect of lurasidone on attaining cross-sectional recovery (defined as combined symptomatic and functional remission) at week 6 . Evaluations of explanatory factors for cross-sectional recovery at week 6 and at month 3 of the extension study were conducted using multivariate logistic regression, controlling for treatment, baseline MADRS and SDS scores, and region. Predictors of sustained recovery at month 3 of the extension were not performed due to sample size limitations.

Moderator analyses were performed using a statistical interaction test in the logistic regression model to compare treatment effects in patients with two versus three protocol-specified manic symptoms at study baseline. Exploratory analyses were performed to evaluate rates of sustained recovery among patients enrolled at U.S. sites. Association between symptomatic remission and functional remission was assessed using the phi $(\phi)$ coefficient. The concordance between these two remission outcomes controlling for treatment was evaluated using overall kappa (к).

\section{Results}

A total of 211 patients were randomized to receive once-daily lurasidone $20-60 \mathrm{mg}(n=109)$ or placebo $(n=102)$. Of these, 208 patients (lurasidone $n=108$, placebo $n=100$ ) received at least one dose of study medication and comprised the intent-to-treat population. Of the 59 patients enrolled at U.S. sites, 52 patients $(89.7 \%)$ completed the 6-week, double-blind, randomized phase, of whom 48 (lurasidone-to-lurasidone $n=29$; placebo-to-lurasidone $n=19$ ) enrolled in the 3-month open-label extension study.

The demographic and clinical characteristics are summarized in Table 1 . At week 6, a significantly higher proportion of lurasidone-treated patients met the criteria for cross-sectional recovery using the MADRS total score $<12$ and all SDS domain scores $<3$ criteria $(31.1 \%$, $33 / 106)$ compared to the placebo group $(12.2 \%, 12 / 98$, $p=0.002$, number needed to treat $[N N T]=6$, last observation carried forward [LOCF]) (Figure 1). In a sensitivity analysis using an MADRS total score $<8$ and all SDS domain scores $<2$, the rates of cross-sectional recovery at week 6 were $19.8 \%(21 / 106)$ for lurasidone versus $10.2 \%(10 / 98)$ for placebo $(p<0.05, N N T=11)$ (Figure 1).

A significantly higher proportion of patients in the lurasidone group $(49.1 \%, 53 / 108)$ than in the placebo group $(23.0 \%, 23 / 100)$ met the symptomatic remission criteria (MADRS $<12)$ at week $6(p<0.001, N N T=4)$ (Figure 2). Using a more stringent MADRS score criterion (MADRS $\leq 8$ ), the proportion of lurasidonetreated patients attaining symptomatic remission was also significantly higher $(36.1 \%, 39 / 108)$ compared to the placebo group at week $6(17.0 \%, 17 / 100 ; p=0.001$, $N N T=6$ ) (Figure 2).

A significantly higher proportion of patients in the lurasidone group than in the placebo group met the functional remission criteria (all SDS domain scores $\leq 3$ ) at week 6 , with $38.7 \%(41 / 106)$ in the lurasidone group versus $18.4 \%(18 / 98)$ in the placebo group $(p=0.002$, $N N T=5)$. Lurasidone was also superior to placebo in achieving functional remission across the three SDS

\begin{tabular}{|c|c|c|c|c|}
\hline \multirow[b]{2}{*}{ Characteristics } & \multirow{2}{*}{$\begin{array}{c}\text { Lurasidone } \\
(n=109) \\
n\end{array}$} & \multirow{2}{*}{\multicolumn{3}{|c|}{$\begin{array}{l}\text { Placebo } \\
(n=100)\end{array}$}} \\
\hline & & $\%$ & & $\%$ \\
\hline Male & 36 & $33.0 \%$ & 28 & $28.0 \%$ \\
\hline \multicolumn{5}{|l|}{ Race } \\
\hline White & 94 & $86.2 \%$ & 86 & $86.0 \%$ \\
\hline Black or African American & 14 & $12.8 \%$ & 12 & $12.0 \%$ \\
\hline Other & 1 & $0.9 \%$ & 2 & $2.0 \%$ \\
\hline \multicolumn{5}{|l|}{ Region } \\
\hline Europe & 75 & $68.8 \%$ & 74 & $74.0 \%$ \\
\hline United States & 34 & $31.2 \%$ & 26 & $26.0 \%$ \\
\hline \multicolumn{5}{|c|}{ Current number of mixed features } \\
\hline Two & 68 & $62.4 \%$ & 63 & $63.0 \%$ \\
\hline Three & 41 & $37.6 \%$ & 37 & $37.0 \%$ \\
\hline
\end{tabular}




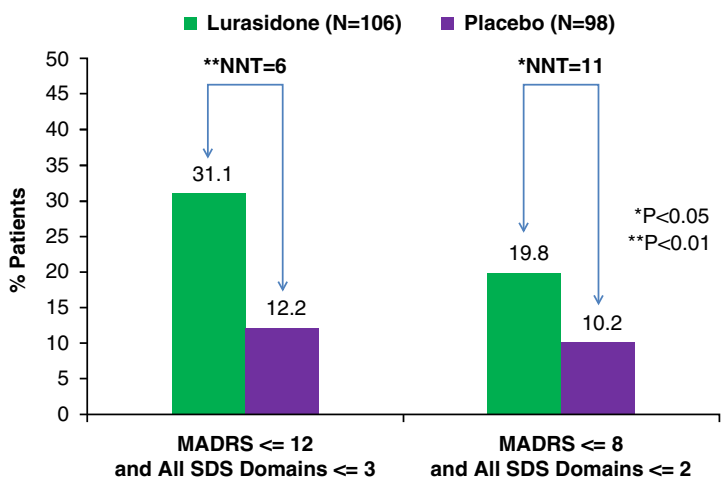

FIGURE 1. Cross-sectional recovery at week 6 (LOCF, intention-to-treat [ITT] population). ${ }^{*} p<0.05,{ }^{* *} p<0.01$. Four ITT subjects had missing SDS data. A logistic regression model that included terms for treatment, region, and baseline MADRS and SDS scores was applied. Cross-sectional recovery at week 6 was defined as combined symptomatic and functional recovery at week 6.

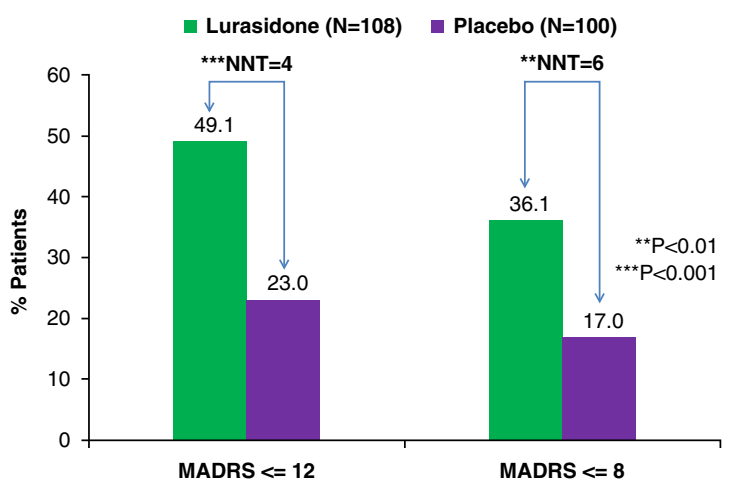

FIGURE 2. Symptomatic remission at week 6 (LOCF, ITT population). ${ }^{* *} p<0.01,{ }^{* * *} p<0.001$. A logistic regression model that included terms for treatment, region, and baseline MADRS score was applied.

domains (SDS domain $\leq 3)$ : work/school $(p=0.001$, $N N T=3)$; social life $(p<0.001, N N T=4)$; and family life $(p<0.001, N N T=4)$. Using a more stringent SDS score criterion (all SDS domain scores $\leq 2$ ), the proportion of patients achieving functional remission remained significantly higher in the lurasidone group $(31.1 \%, 33 / 106)$ compared to the placebo group $(14.3 \%$, 14/98; $p=0.005, N N T=6$ ) (Figure 3).

Reduction in depressive symptoms from baseline to week 6 mediated functional remission at week 6 $\left(p<0.001, \quad \chi^{2}=39.58, d f=1\right)$. The concordance between symptomatic remission and functional remission was $77.9 \%(159 / 204$, overall $\kappa$ coefficient controlling for treatment $=0.47,95 \%$ confidence interval $\left.\left[C_{95 \%}\right]=[0.35,0.60] ; \phi=0.52\right)$. Demographics and baseline MADRS and SDS scores had been assessed but were found to be statistically nonsignificant predictors for cross-sectional recovery at week 6 .

The protocol-specified number of manic symptoms at baseline was a significant moderator of cross-sectional

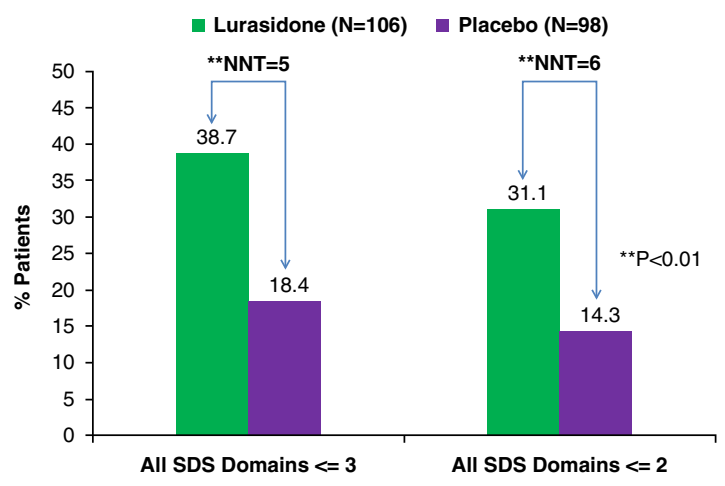

FIGURE 3. SDS functional remission at week 6 (LOCF, ITT population). ${ }^{* *} p<0.01$. Four ITT subjects had missing SDS data. A logistic regression model that included terms for treatment, region, and baseline MADRS and SDS scores was applied.

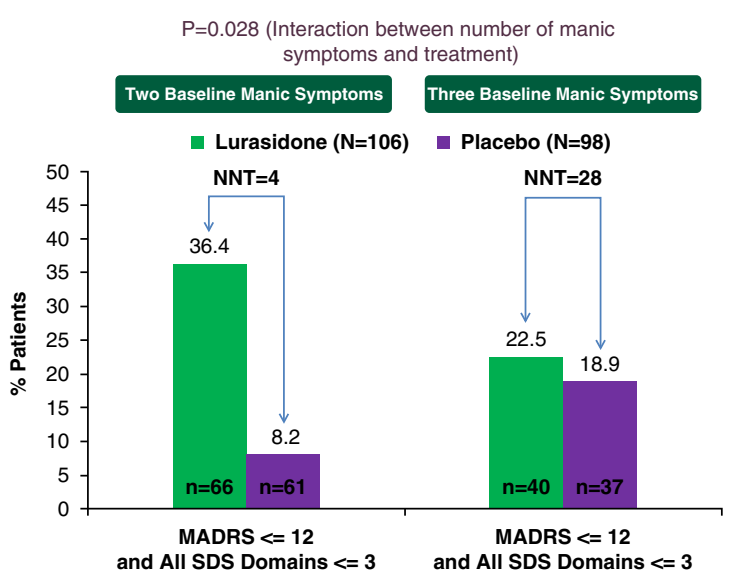

FIGURE 4. Significant moderator of cross-sectional recovery at week 6 between lurasidone and placebo: baseline number of manic symptoms in treatment of MDD with mixed features. ${ }^{*} p<0.05$. Four ITT subjects had missing SDS data. A logistic regression model that included terms for treatment, region, baseline MADRS and SDS scores, number of manic symptoms, and number of manic symptom $\times$ treatment was applied. Crosssectional recovery at week 6 was defined as combined symptomatic and functional recovery at week 6 .

recovery at week 6 ( $p=0.028$ for treatment-by-number of manic symptoms at baseline). The effect size for attaining cross-sectional recovery at week 6 with lurasidone treatment (vs. placebo) was significantly higher $(p=0.028)$ in patients with two manic symptoms (lurasidone $36.4 \%$, 24/66; placebo $8.2 \%$, $5 / 61 ; N N T=4)$ compared to three manic symptoms (lurasidone $22.5 \%$, 9/40; placebo $18.9 \%, \quad 7 / 37$; $N N T=28$ ) (Figure 4).

In the 3-month, open-label, extension study, among the U.S. lurasidone-to-lurasidone group patients, the rates of recovery increased from $27.6 \%(8 / 29)$ at week 6 to $34.6 \%(9 / 26)$ at month 1 , and to $41.7 \%$ $(10 / 24)$ at month 3 of the extension study. A similar trend was observed for the placebo-to-lurasidone 


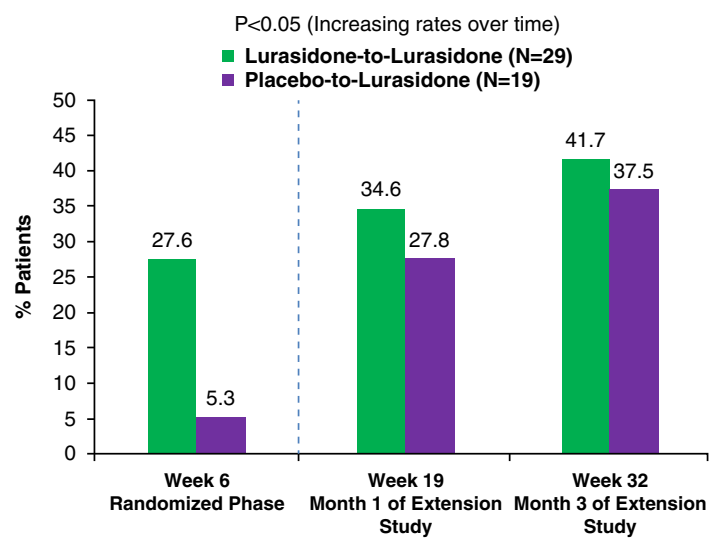

FIGURE 5. Cross-sectional recovery over the acute and extension treatment periods (U.S. sites only). ${ }^{*} p<0.05$ (increasing linear slope). Lurasidone-tolurasidone: lurasidone in the 6 -week randomized phase followed by flexible dosing of lurasidone in the 3-month extension study. Placebo-to-lurasidone: placebo in the 6-week randomized phase followed by flexible dosing of lurasidone in the 3-month extension study. Cross-sectional recovery was defined as combined symptomatic and functional recovery at week 6 in the core phase and at months 1 and 3 of the extension study.

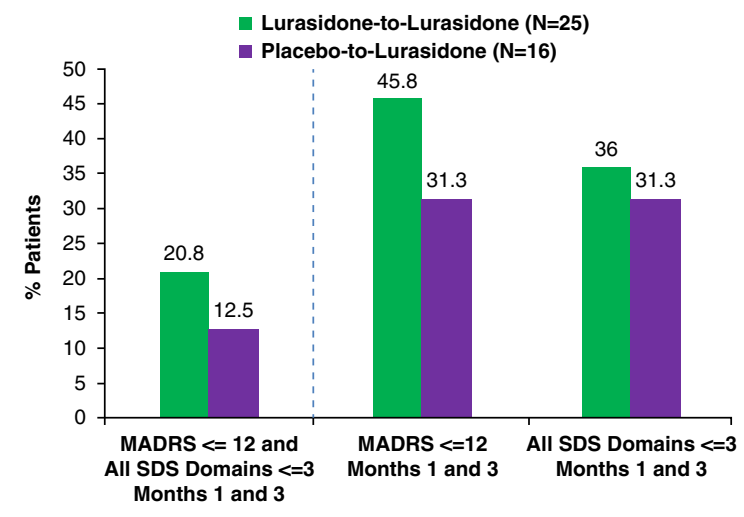

FIGURE 6. Recovery: sustained symptomatic and functional remission (U.S sites only). Lurasidone-to-Iurasidone: Iurasidone in the 6-week randomized phase followed by flexible dosing of lurasidone in the 3-month extension study. Placebo-to-lurasidone: placebo in the 6-week randomized phase followed by flexible dosing of lurasidone in the 3-month extension study. "Sustained recovery" was defined as meeting criteria for both symptomatic and functional remission at both months 1 and 3 of the extension study.

group, whose recovery rates increased from $5.3 \%(1 / 19)$ at week 6 to $27.8 \%(5 / 18)$ and $37.5 \%(6 / 16)$ for the month 1 and month 3 endpoints, respectively $(p<0.05)$ (Figure 5).

The proportions of lurasidone-treated patients achieving "sustained recovery," defined as meeting criteria for combined symptomatic remission $(\mathrm{MADRS}<12$ ) and functional remission (all SDS domain scores $<3$ ) for both months 1 and 3 of the extension study, were $20.8 \%$ $(5 / 24)$ and $12.5 \%(2 / 16)$ in the lurasidone-to-lurasidone and placebo-to-lurasidone groups, respectively (Figure 6). The proportion of patients attaining symptomatic remission sustained at both months 1 and 3 were $45.8 \%$ $(11 / 24)$ in the lurasidone-to-lurasidone group and $31.3 \%$ $(5 / 16)$ in the placebo-to-lurasidone group. The proportions of patients attaining functional remission sustained for both months 1 and 3 were $36.0 \%(9 / 25)$ in the lurasidoneto-lurasidone group and $31.3 \%(5 / 16)$ in the placebo-tolurasidone group.

Reduction in depressive symptoms from core study baseline to month 3 was significantly associated with functional remission at month 3 of the extension study $\left(p=0.006, \chi^{2}=7.65, d f=1\right.$; LOCF $)$. The concordance between symptomatic remission and functional remission at month 3 (LOCF) was 65.9\% (29/44) (overall $\kappa$ coefficient controlling for treatment $=0.31, C I_{95 \%}=$ $[0.03,0.59] ; \phi=0.31)$. The change in CGI-S scores from core study baseline to month 3 was significantly associated with cross-sectional recovery at month 3 $\left(p=0.002, \chi^{2}=9.32, d f=1\right)$.

\section{Discussion}

The present research is the first study, to our knowledge, of recovery in major depressive disorder with subthreshold hypomanic symptoms (mixed features), as defined by the integration of symptomatic remission and functional improvement. ${ }^{23}$ While the construct of "recovery" from episodes of mood disorder has often been defined based mainly, if not solely, on the basis of affective symptom resolution sustained for at least 8 weeks, ${ }^{21,28}$ a more rigorous definition of "recovery" that incorporates the absence of functional impairment was proposed over 30 years ago in the Research Diagnostic Criteria. ${ }^{29}$ However, rigorous definitions of "recovery" that incorporate both symptomatic remission and functional improvement as indicators of treatment success have been used in only a handful of outcome studies (e.g., the National Institute of Mental Health Collaborative Depression Study) by Solomon et al. ${ }^{30}$ and Loebel et al. ${ }^{23}$

Judd et al. ${ }^{31}$ proposed a definition of major depressive episode recovery as an 8-week period free of all symptoms associated with the previous major depressive episode (asymptomatic recovery). In the Sequenced Treatment Alternatives to Relieve Depression $\left(\mathrm{STAR}_{*} \mathrm{D}\right)$ trial, which enrolled outpatients with nonpsychotic major depressive disorder, ${ }^{32}$ the primary outcome was symptomatic remission defined as a HAM-D score $<7$. A total of $27.5 \%$ of patients achieved remission after 8 weeks of treatment with citalopram (level 1 treatment). In the Systematic Treatment Enhancement Program for Bipolar Disorder (STEP-BD) study in patients with major depressive episode associated with bipolar I or bipolar II disorder, the primary outcome was durable recovery (defined as at least 8 consecutive weeks of euthymia-no more than two depressive or two manic symptoms). ${ }^{33}$ For patients receiving a mood stabilizer plus adjunctive 
antidepressant therapy and a mood stabilizer plus matching placebo, a total of 23.5 and $27.3 \%$ of patients, respectively, achieved recovery. In a recent 6-week, randomized, double-blind, placebo-controlled study of olanzapine in bipolar I depression, the rates of remission (defined as MADRS $<8$ ) and recovery (defined as MADRS $<12$ for $>4$ weeks plus treatment completion) for olanzapine were $38.5 \%$ (vs. $29.2 \%$ for placebo) and $13.7 \%$ (vs. $9.4 \%$ for placebo), respectively. ${ }^{34}$ All of these definitions were based on asymptomatic remission for 6 to 8-week durations (asymptomatic recovery).

In our post-hoc analysis of a placebo-controlled trial, lurasidone was found to significantly improve rates of "cross-sectional recovery" (i.e., a combination of symptomatic remission and functional remission) at the 6-week study endpoint, with moderate effect size $(N N T=6)$. In the 3-month open-label extension of the study (limited to patients enrolled at U.S. sites), sustained recovery was attained by $20.8 \%$ of patients who continued on lurasidone in the extension study, and by $12.5 \%$ of patients who switched from placebo to lurasidone in the extension study. Higher cross-sectional recovery rates were observed for lurasidone-tolurasidone patients $(41.7 \%)$ compared to placeboto-lurasidone patients $(37.5 \%)$ after 3 months of extension-study treatment. Rates of recovery increased over time in patients treated with both lurasidone and placebo in the acute and extension studies, suggesting that responsivity to lurasidone was not reduced based on initial assignment to placebo.

The "cross-sectional" and "sustained recovery" rates reported for lurasidone in this post-hoc analysis using multidimensional recovery criteria are at least similar and may be higher than the recovery rates reported in prior mood-disorder studies that used less stringent criteria at generally shorter treatment durations of 68 weeks (as noted above). Our findings therefore support the effectiveness of lurasidone in attainment of recovery, rigorously defined, in patients with a severe form of MDD.

While both symptomatic and functional improvement are important components of full recovery, ${ }^{21,23,35-40}$ and may be linked, as demonstrated in several studies, ${ }^{23,35-38}$ they are not necessarily always coincident. ${ }^{21,23,35-37,40-43}$ The observation that functional recovery often lags behind symptomatic or syndromal recovery ${ }^{41}$ may account for this lack of coincidence in the components of recovery. Findings from this analysis indicated that there was a moderately high level of concordance between symptomatic remission and functional remission at the endpoints of both the core $(77.9 \%)$ and extension $(65.9 \%)$ studies.

In our study, functional remission at week 6 was found to be mediated through improvement in depressive symptoms from baseline to week 6 , while the overall improvement in CGI-S score mediated recovery at the extension-study endpoint. These results are consistent with a recent study by Rajagopalan and colleagues ${ }^{44}$ which found that functional improvement in patients with bipolar depression was mediated through the reduction of depressive symptoms.

We defined mixed features in our study as the presence of two or three protocol-specified manic symptoms for at least 2 weeks prior to screening. Previous reports have suggested that a poorer prognosis and greater functional impairment were associated with mixed mood symptoms of opposite polarity (e.g., mixed mania) compared to unipolar depression. ${ }^{2,11,12,45}$ In this analysis, we found that number of manic symptoms at baseline was a significant moderator for recovery (crosssectional) at week 6 , using a statistical interaction test in the full analysis sample $(N=204)$. Patients with two manic symptoms (occurring on most days for at least 2 weeks prior to screening) had a greater likelihood of attaining cross-sectional recovery at week $6(N N T=4$ for lurasidone vs. placebo) than subjects with three manic symptoms $(N N T=28$ for lurasidone vs. placebo). However, we note that, due to the limited number of concomitant manic symptoms present in each subsample, together with their small size and variability in treatment response, definitive conclusions are precluded regarding whether subthreshold manic symptoms during major depression can attenuate treatment efficacy via a gradient or threshold effect. Interestingly, the proportion of lurasidone-treated patients attaining combined symptomatic and functional remission at week 6 was similar in patients with two subthreshold hypomanic symptoms $(36.4 \%)$ compared to lurasidone-treated patients with bipolar depression (33.3\%). ${ }^{23}$ Further research is needed to confirm these exploratory findings, which suggest that the number and possibly the type of manic symptoms may moderate the likelihood of symptomatic and functional remission in the treatment of MDD with mixed features.

Several limitations of this post-hoc analysis should be noted. The criteria for mixed features in our study were similar to, but not exactly the same as, the DSM-5 mixedfeatures specifier. ${ }^{14}$ The moderator analysis was based on a statistical interaction test utilizing a relatively small full analysis sample. We also note that only patients at U.S. sites were eligible for the extension study (which was not conducted outside the States), which limited the sample size for the extension study. While we assume that the extension study recovery data presented here are generalizable to the entire study population, this cannot be definitively established. These findings should therefore be considered preliminary and exploratory. Further investigations to confirm the long-term effectiveness of lurasidone in this novel patient population are thus warranted. 


\section{Conclusions}

In this post-hoc analysis of a placebo-controlled study with open-label extension, involving patients with MDD and subthreshold hypomanic symptoms (mixed features), lurasidone was found to have significantly improved the rate of recovery at 6 weeks (vs. placebo), which was sustained after an additional 3 months of extension-study treatment. The presence of two (vs. three) manic symptoms moderated recovery at the acute study endpoint. These results underscore the importance of assessing combined symptomatic and functional remission in the evaluation of long-term recovery outcome. Further investigation and validation of our criteria for recovery and predictors of recovery in patients with MDD with mixed features are warranted.

\section{Disclosures}

Joseph F. Goldberg reports personal fees from Sunovion Pharmaceuticals Inc. during the conduct of the study, and personal fees from Merck, from Takeda-Lundbeck, from Vanda Pharmaceuticals, from WebMD, and from Medscape outside the submitted work. In addition, Dr. Goldberg has published a book with American Psychiatric Publishing Inc. with royalties paid.

Cynthia Siu reports personal fees from Sunovion Pharmaceuticals Inc. during the conduct of the study, and personal fees from Pfizer Inc. and the Chinese University of Hong Kong outside the submitted work.

Daisy Ng-Mak reports personal fees from Sunovion Pharmaceuticals Inc. during the conduct of the study.

Chien-Chia Chuang reports personal fees from Sunovion Pharmaceuticals Inc. during the conduct of the study.

Krithika Rajagopalan reports personal fees from Sunovion Pharmaceuticals Inc. during the conduct of the study.

Antony Loebel reports personal fees from Sunovion Pharmaceuticals Inc. during the conduct of the study.

\section{REFERENCES:}

1. Judd LL, Akiskal HS. The prevalence and disability of bipolar spectrum disorders in the US population: re-analysis of the ECA database taking into account subthreshold cases. J Affect Disord. 2003; 73(1-2): 123-131.

2. Angst J, Cui L, Swendsen J, et al. Major depressive disorder with subthreshold bipolarity in the National Comorbidity Survey Replication. Am J Psychiatry. 2010; 167(10): 1194-1201. Epub ahead of print Aug 16. https://www.ncbi.nlm.nih.gov/pmc/articles/ PMC3145248/. Accessed January 14, 2017.

3. Hoertel N, Le Strat Y, Angst J, et al. Subthreshold bipolar disorder in a US national representative sample. prevalence, correlates, and perspectives for psychiatric nosography. J Affect Disord. 2013; 146(3): 338-347. Epub ahead of print Oct 3, 2012.

4. Angst J, Azorin JM, Bowden CL, et al. Prevalence and characteristics of undiagnosed bipolar disorders in patients with a major depressive episode: the BRIDGE study. Arch Gen Psychiatry. 2011; 68(8): 791-798. http://jamanetwork.com/journals/jamapsychiatry/ fullarticle/1107421. Accessed January 14, 2017.

5. Angst J, Gamma A, Bowden CL, et al. Evidence-based definitions of bipolar-I and bipolar-II disorders among 5,635 patients with major depressive episodes in the BRIDGE Study: validity and comorbidity. Eur Arch Psychiatry Clin Neurosci. 2013; 263(8): 663-673. Epub ahead of print Jan 31.

6. Benazzi F, Akiskal HS. Psychometric delineation of the most discriminant symptoms of depressive mixed states. Psychiatry Res. 2006; 141(1): 81-88. Epub ahead of print Nov 28, 2005.

7. Zimmermann P, Brückl T, Nocon A, et al. Heterogeneity of DSM-IV major depressive disorder as a consequence of subthreshold bipolarity. Arch Gen Psychiatry. 2009; 66(12): 1341-1352. http:// jamanetwork.com/journals/jamapsychiatry/fullarticle/210481. Accessed January 14, 2017.

8. Perlis RH, Uher R, Ostacher M, et al. Association between bipolar spectrum features and treatment outcomes in outpatients with major depressive disorder. Arch Gen Psychiatry. 2011; 68(4): 351-360. https://www.ncbi.nlm.nih.gov/pmc/articles/PMC3794668/. Accessed January 14, 2017.

9. Perugi G, Angst J, Azorin JM, et al. Mixed features in patients with a major depressive episode. the BRIDGE-II-MIX Study. J Clin Psychiatry. 2015; 76(3): e351-e358.

10. McIntyre RS, Soczynska JK, Cha DS, et al. The prevalence and illness characteristics of DSM-5-defined "mixed feature specifier" in adults with major depressive disorder and bipolar disorder: results from the International Mood Disorders Collaborative Project. J Affect Disord. 2014; 172: 259-264. Epub ahead of print Oct 12.

11. Nusslock R, Frank E. Subthreshold bipolarity: diagnostic issues and challenges. Bipolar Disord. 2011; 13(7-8): 587-603. https://www. ncbi.nlm.nih.gov/pmc/articles/PMC3397420/. Accessed January 14, 2017.

12. Smith DJ, Forty L, Russell E, et al. Sub-threshold manic symptoms in recurrent major depressive disorder are a marker for poor outcome. Acta Psychiatr Scand. 2009; 119(4): 325-329. Epub ahead of print Dec 16, 2008.

13. Popovic D, Vieta E, Azorin JM, et al. Suicide attempts in major depressive episode: evidence from the BRIDGE-II-Mix Study. Bipolar Disord. 2015; 17(7): 795-803. Epub ahead of print Sep 29.

14. American Psychiatric Association. Diagnostic and Statistical Manual of Mental Disorders, 5th ed. Arlington, VA: American Psychiatric Publishing; 2013.

15. Ishibashi T, Horisawa $\mathrm{T}$, Tokuda $\mathrm{K}$, et al. Pharmacological profile of lurasidone, a novel antipsychotic agent with potent 5hydroxytryptamine $7\left(5-\mathrm{HT}_{7}\right)$ and $5-\mathrm{HT}_{1 \mathrm{~A}}$ receptor activity. J Pharmacol Exp Ther. 2010; 334(1): 171-181. Epub ahead of print Apr 19. http://jpet.aspetjournals.org/content/334/1/171.long. Accessed January 14, 2017.

16. Hedlund $\mathrm{PB}$. The $5-\mathrm{HT}_{7}$ receptor and disorders of the nervous system: an overview. Psychopharmacology (Berl.). 2009; 206(3): 345-354. https://www.ncbi.nlm.nih.gov/pmc/articles/ PMC2841472/. Accessed January 14, 2017.

17. Cates LN, Roberts AJ, Huitron-Resendiz S, et al. Effects of lurasidone in behavioral models of depression: role of the $5-\mathrm{HT}_{7}$ receptor subtype. Neuropharmacology. 2013; 70: 211-217. Epub ahead of print Feb 13.

18. Loebel A, Cucchiaro J, Silva R, et al. Lurasidone monotherapy in the treatment of bipolar I depression: a randomized, double-blind, placebo-controlled study. Am J Psychiatry. 2014; 171(2): 160-168. http://ajp.psychiatryonline.org/doi/pdf/10.1176/appi. ajp.2013.13070984. Accessed January 14, 2017.

19. Loebel A, Cucchiaro J, Silva R, et al. Lurasidone as adjunctive therapy with lithium or valproate for the treatment of bipolar I depression: a randomized, double-blind, placebo-controlled study. 
Am JPsychiatry. 2014; 171(2): 169-177. http://ajp.psychiatryonline. org/doi/pdf/10.1176/appi.ajp.2013.13070985. Accessed January 14, 2017.

20. Suppes T, Silva R, Cucchiaro J, et al. Lurasidone for the treatment of major depressive disorder with mixed features: a randomized. double-blind. placebo-controlled study. Am J Psychiatry. 2016; 173(4): 400-407. Epub ahead of print Nov 10, 2015.

21. Tohen M, Frank E, Bowden CL, et al. The International Society for Bipolar Disorders (ISBD) Task Force report on the nomenclature of course and outcome in bipolar disorder. Bipolar Disord. 2009; 11(5): 453-473.

22. Goldberg JF, Harrow M. A 15-year prospective follow-up of bipolar affective disorders, comparison with unipolar depression. Bipolar Disord. 2011; 13(2): 155-163.

23. Loebel A, Siu C, Rajagopalan K, Pikalov A, Cucchiaro J, Ketter TA. Recovery in bipolar depression: Post-hoc analysis of a placebocontrolled lurasidone trial followed by a long-term continuation study. J Affect Disord. 2015; 186: 376-382. Epub ahead of print Aug 5. http://www.jad-journal.com/article/S01650327(15)30168-3/pdf. Accessed January 14, 2017.

24. Montgomery SA, Åsberg M. A new depression scale designed to be sensitive to change. Br J Psychiatry. 1979; 134: 382-389.

25. First MB, Williams JBW, Spitzer RL, Gibbon M. Structured Clinical Interview for DSM-IV-TR Axis I Disorders, Clinical Trials Version (SCID-CT). New York: New York State Psychiatric Institute; 2007. https://eprovide.mapi-trust.org/instruments/structured-clinicalinterview-for-dsm-iv-axis-i-disorders. Accessed January 14, 2017.

26. Guy W. Early Clinical Drug Evaluation Assessment Manual for Psychopharmacology Publication ADM 76-338 Washington, DC: U.S. Department of Health, Education, and Welfare; 1976. P. 218-222. https://archive.org/details/ecdeuassessmentm1933guyw. Accessed January 14, 2017.

27. Sheehan DV, Hamett-Sheehan K, Raj BA. The measurement of disability. Int Clin Psychopharmacol. 1996; 11(Suppl. 3): S89-S95.

28. Goldberg JF, Perlis RH, Ghaemi SN, et al. Adjunctive antidepressant use and symptomatic recovery among bipolar depressed patients with concomitant manic symptoms: findings from the STEP-BD. Am J Psychiatry. 2007; 164(9): 1348-1355. http://ajp. psychiatryonline.org/doi/pdf/10.1176/appi.ajp.2007.05122032. Accessed January 14, 2017.

29. Spitzer RL, Endicott J, Robins E. Research diagnostic criteria: rationale and reliability. Arch Gen Psychiatry. 1978; 35(6): 773-782. http://jamanetwork.com/journals/jamapsychiatry/ fullarticle/491943. Accessed January 14, 2017.

30. Solomon DA, Fiedorowicz JG, Leon AC, et al. Recovery from multiple episodes of bipolar I depression. J Clin Psychiatry. 2013; 74(3): e205-e211. https://www.ncbi.nlm.nih.gov/pmc/articles/ PMC3837577/. Accessed January 14, 2017.

31. Judd LL, Schettler PJ, Rush J, et al. A new empirical definition of major depressive episode recovery and its positive impact on future course of illness. J Clin Psychiatry. 2015; 77(8): 1065-1073.

32. Trivedi MH, Rush J, Wisniewski SR, et al. Evaluation of outcomes with citalopram for depression using measurement-based care in STAR ${ }^{*}$ D: implications for clinical practice. Am J Psychiatry. 2006;
163(1): 28-40. http://ajp.psychiatryonline.org/doi/pdf/10.1176/ appi.ajp.163.1.28. Accessed January 14, 2017.

33. Sachs GS, Nierenberg AA, Calabrese JR, et al. Effectiveness of adjunctive antidepressant treatment for bipolar depression. $N$ Engl J Med. 2007; 356(17): 1711-1722. Epub ahead of print Mar 28. http://www.nejm.org/doi/pdf/10.1056/NEJMoa064135. Accessed January 14, 2017.

34. Tohen M, McDonnell DP, Case M, et al. Randomised, double-blind, placebo-controlled study of olanzapine in patients with bipolar I depression. Br J Psychiatry. 2012; 207(5): 376-382. Epub ahead of print Aug 23. http://bjp.rcpsych.org/content/201/5/376.long. Accessed January 14, 2017.

35. Sheehan KH, Sheehan DV. Assessing treatment effects in clinical trials with the discan metric of the Sheehan Disability Scale. Int. Clin. Psychopharmacol. 2008; 23(2): 70-83.

36. Sheehan DV, Myers AL, Prakash A, et al. The relationship between functional outcomes and the treatment of anxious and painful somatic symptoms in patients with generalized anxiety disorder. Curr Med Res Opin. 2008; 24(9): 2457-2466. Epub ahead of print Jul 24.

37. Mancini M, Sheehan DV, Demyttenaere K, et al. Evaluation of the effect of duloxetine treatment on functioning as measured by the Sheehan Disability Scale, pooled analysis of data from six randomized, double-blind, placebo-controlled clinical trials. Int Clin Psychopharmacol. 2012; 27(6): 298-309.

38. Bijl RV, Ravelli A. Current and residual functional disability associated with psychopathology: findings from the Netherlands Mental Health Survey and Incidence Study (NEMESIS). Psychol Med. 2000; 30(3): 657-668.

39. Simon GE, Revicki D, Heiligenstein J, et al. Recovery from depression, work productivity and health care costs among primary care patients. Gen Hosp Psychiatry. 2000; 22(3): 153-162.

40. McIntyre RS, Lee Y, Mansur RB. Treating to target in major depressive disorder: response to remission to functional recovery. CNS Spectr. 2015; 20(Suppl. 1): 17-31.

41. van der Voort TY, Seldenrijk A, van Meijel B, et al. Functional versus syndromal recovery in patients with major depressive disorder and bipolar disorder. J Clin Psychiatry. 2015; 76(6): e809-e814.

42. Conradi HJ, Ormel J, de Jonge P. Presence of individual (residual) symptoms during depressive episodes and periods of remission: a 3-year prospective study. Psychol Med. 2011; 41(6): 1165-1174.

43. Mojtabai R. Residual symptoms and impairment in major depression in the community. Am J Psychiatry. 2001; 158(10): 1645-1651. http://ajp.psychiatryonline.org/doi/pdf/10.1176/appi.ajp.158.10.1645. Accessed January 14, 2017.

44. Rajagopalan K, Bacci ED, Wyrwich KW, Pikalov A, Loebel A. The direct and indirect effects of lurasidone monotherapy on functional improvement among patients with bipolar depression: results from a randomized placebo-controlled trial. Int J Bipolar Disord. 2016; 4(1): Epub ahead of print Mar 16. https://www.ncbi.nlm.nih.gov/ pmc/articles/PMC4792823/. Accessed January 14, 2017.

45. Vieta E, Valentí M. Pharmacological management of bipolar depression: acute treatment, maintenance, and prophylaxis. CNS Drugs. 2013; 27(7): 515-529. 